\title{
Variant Branching Patterns of External Carotid Artery -Pharyngo - Occipital Trunk \& Occipito - Auricular Trunk
}

\author{
Dr.Navakalyani.T, 2. Dr Janaki.V.* , 3. Dr. Sumalatha , \\ ${ }^{1}$ Associate Professor Of Anatomy, Osmania Medical College, Hyderabad, Telangana State, Indiaassistant \\ ${ }^{2}$ Professor Of Anatomy, Osmania Medical College, Hyderabad, Telangana State, India. E-Mail Address: ${ }^{3}$ \\ ${ }^{3}$ Assistant Professor Of Anatomy, Osmania Medical College, Hyderabad, Telangana State, India.
}

\begin{abstract}
:
Introduction: Variations in the branching pattern of the external carotid artery are well documented as it is the main source of nutrition to the structures of head and neck. The variations in the branching pattern of ECA are important for surgeons during plastic and reconstructive surgeries of head, neck and face to avoid iatrogenic injuries and it is also important for radiologists for interpretation of angiograms of the face and neck regions.

Material \& Methods The present study was done on 60 dead foetuses and 15 adult cadavers to find out any anomalous patterns of branching of external carotid artery as a part of post graduation research work. The common carotid artery and its terminal vessels, external and internal carotid arteries were dissected on both sides. All the branches of external carotid artery were traced.

Results: Along with normal branching pattern, variations like Pharyngo - Occipital trunk, Occipito - Auricular trunk, bifurcation of common carotid artery at higher level and higher origin ascending pharyngeal artery were observed in this study.

Conclusion: As these vessels show great variability, a better anatomical knowledge about these variations is useful to surgeons for ligation of the vessels during head and neck surgeries and for radiologist during the interpretation of angiograms. Knowledge of possible anatomical variations of the ECA is especially important in facio-maxillary and neck surgeries.
\end{abstract}

Keywords: Common Carotid Artery, External Carotid Artery, Internal Carotid Artery, Ascending Pharyngeal Artery, Pharyngo - Occipital trunk, Occipito-Auricular trunk

\section{Introduction}

Common carotid arteries (CCA) are the largest bilateral arteries of the head and neck. CCA of both sides divide at the upper border of the thyroid cartilage at intervertebral disc level between the third and fourth cervical vertebrae into external and internal carotid arteries (Takenoshita, 1983) ${ }^{[1]}$.External carotid artery (ECA) extends from the level of upper border of the lamina of thyroid cartilage to a point behind the neck of the mandible. During its course it gives altogether eight branches, of which the superficial temporal and maxillary arteries are its terminal branches (Dutta, 1994) ${ }^{[2]}$. The ascending pharyngeal artery is the first and medial branch of ECA. After its origin it ascends between internal carotid artery (ICA) and side of pharynx. The ventral branches- Superior thyroid artery (STA) passes downwards and medially to supply the thyroid gland, Lingual artery (LA)- the main artery of tongue arises at the tip of greater horn of the hyoid and disappears behind the hyoglossus muscle and tortuous Facial artery (FA) that has a looped course in the digastric triangle and enters the face for its supply. The posterior branches, Occipital artery (OA) runs posterosuperiorly to supply the posterior aspect of the scalp and Posterior auricular artery (PAA)to the auricle and the scalp above it. The Maxillary artery is having a course in the infratemporal fossa and nourishes the structures of that region and Superficial temporal artery provides blood supply to the lateral aspect of scalp and face. ECA provides rich vascularity to the structures of head and neck. The branches of ECA are the key landmarks for adequate exposure and appropriate placement of cross clamps on the carotid artery. So the knowledge of carotid arterial system is useful to minimize the postoperative complications in the bloodless surgical field (Nakamasa, 2005) ${ }^{[3]}$. The variations in the branching pattern of ECA are important for surgeons during plastic and reconstructive surgeries of head neck and face to avoid iatrogenic injuries and it is also important for radiologists for interpretation of angiograms of the face and neck regions. 
Variant Branching Patterns Of External Carotid Artery-Pharyngo-Occipital Trunk \& Occipito..

\section{Material And Methods}

the material chosen for dissection are the dead fetuses collected from the obstetrics and gynaecology, Govt General Hospital , Guntur. Adult bodies which are allotted for 1MBBS students of GMC are chosen for dissection. all specimens are well preserved in formalin before dissection. A total number of 75 specimens are dissected (15 adults and 60 foetuses). The dissection is made layer by layer according to Cunningham's manual and branches from external carotid artery, their course and whether they are in normal pattern or any varations in their origin and course were noted.

\section{Observations And Results}

Usually Occipital artery arises from the posterior aspect of external carotid artery opposite the origin of the facial artery. We found three variations in our present study out of 60 fetuses, three fetuses showed variation, that is posterior auricular artery arises from occipital artery (Fig-1\&2) as occipito -auricular trunk (5\%).In the present work the mode of origin of both carotids (external \& internal) in all the specimens is from common carotid artery. No variation in the origin is observed. But variation in the level of origin in two specimens is observed, these arises from the higher level than the normal. (Fig-3)

Table No - 1 Higher Level Of Origin Of External Carotid Artery

\begin{tabular}{|l|l|}
\hline Name of the author & Incidence \\
\hline Kantor & $2 \%$ \\
\hline R.J.Romanes & Occasional \\
\hline Pointer & $1 \%$ \\
\hline Persent work & $2 \%$ \\
\hline
\end{tabular}

Ascending pharyngeal artery arises from Occipital artery instead of external carotid artery in one foetus. (Fig-3)

Table No -2 Origin of ascending pharyngeal artery from occipital artery

\begin{tabular}{|l|l|}
\hline Name of the author & Incidence \\
\hline W.Henry Hollinshed & $14 \%$ \\
\hline Anil Afitab \&associates & $14 \%$ \\
\hline Ernest D.Gardner & Occasional \\
\hline Present work & $1 \%$ \\
\hline
\end{tabular}

Other variations we found in our present study are superior thyroid artery arise from bifurcation of common carotid instead of external carotid artery in six fetuses. (Fig-4)

Table No - 3 Origin of superior thyroid artery is from the bifurcation of common carotid artery

\begin{tabular}{|l|l|}
\hline Name of the author & Incidence \\
\hline Faller and Scharrer & $36 \%$ \\
\hline W.Henry Hollinshed & $16 \%$ \\
\hline Quain & $14 \%$ \\
\hline Present work & $8 \%$ \\
\hline
\end{tabular}

Superior thyroid artery arises in common with lingual artery on one foetus.

Table No - 4 Presence of thyro -lingual trunk

\begin{tabular}{|l|l|}
\hline Name of the author & Incidence \\
\hline Quain & $0.7-3 \%$ \\
\hline Present work & $1 \%$ \\
\hline
\end{tabular}

The lingual artery arises in common with facial artery in six fetuses .

Table No - 5 Presence of Linguo-Facial Trunk

\begin{tabular}{|l|l|}
\hline Name of the author & Incidence \\
\hline Henry grey & $43 \%$ \\
\hline W.Henry Hollinshed & $20 \%$ \\
\hline Anne M.R.Agur & $20 \%$ \\
\hline Faller & $10-20 \%$ \\
\hline J.C.Boileau Grant & $10 \%$ \\
\hline Weston D.Gardner & Occasional \\
\hline Ernest D.Gardner & Occasional \\
\hline Present work & $8 \%$ \\
\hline
\end{tabular}


Variant Branching Patterns Of External Carotid Artery-Pharyngo-Occipital Trunk \& Occipito..

\section{Discussion}

The external carotid artery is the terminal branch of common carotid artery along with internal carotid artery. Normal branches of external carotid artery are superior thyroid, lingual, facial arteries of ventral aspect, the occipital and posterior auricular arteries of posterior aspect, ascending pharyngeal artery a medial branch and the maxillary, superficial temporal arteries its terminal branches (Standring 2005) ${ }^{[4]}$. All these branches arise independently according to their land marks. The variations in the branching pattern of ECA were reported in the literature. Zumre et al., in his study on variations of branches of ECA described a linguofacial trunk in $20 \%$ of the cases, a thyrolingual trunk in $2.5 \%$, a thyrolinguofacial trunk in $2.5 \%$, and an occipitoauricular trunk in $12.5 \%$ of the cases (Zumre 2005) ${ }^{[5]}$. In our present study Linguofacial trunk in $8 \%$ cases, Thyro-lingual trunk in $1 \%$ cases, Occipito -auricular trunk in 5\% cases, superior thyroid artery arises from common carotid artery in $8 \%$ cases, Ascending pharyngeal artery from Occipital artery in $1 \%$ cases higher division of common carotid artery in $2 \%$ cases observed. Anatomical knowledge of variations in the branching pattern of the carotid system will be useful in angiographic studies and in surgical procedures of the head and neck region. Along with Linguo-facial trunk and Occipito-auricular trunk, a simultaneous branching of the ECA into the lingual, facial, occipito-auricular and distal part of the ECA was described by Thwin et al., $(2010)^{[6]}$. All these branches were given after superior thyroid artery (Thwin et al., 2010). Normally the APA is the first and medial branch of ECA but the variations in the level of origin of APA was also reported in the literature. The APA is the second and smallest branch arising from the posterior aspect of the ECA (Drake 2005) ${ }^{[7]}$. The origin of the right APA from the bifurcation of the CCA was reported by Anil et al., (Anil2000) ${ }^{[8]}$. The origin of ascending pharyngeal artery from ECA is considered high or low with relation to lingual artery. It was found higher in 66\% and lower origin in 9\% (Nakamasa 2005). In his study on the variations of branches of ECA, Thwin et al., (2010) reported a higher origin of APA. He found this branch at the linguofacial trunk or above the level of lingual artery. Gurbuz et al ${ }^{[9]}$ found carotid trifurcation during routine dissection.

The left common carotid artery gave off three terminal branches: the external carotid, internal carotid, and occipital arteries. The level of trifurcation was $35 \mathrm{~mm}$ above the superior margin of the thyroid cartilage. Further, the superior thyroid artery arose from the common carotid artery instead of the external carotid.Although the common carotid artery usually has no branches, it may occasionally give rise to the vertebral, superior laryngeal, ascending pharyngeal, inferior thyroid or occipital arteries ${ }^{[10]}$. There is one report in which the right common carotid artery bifurcated at a level between the second and the third cervical vertebrae, giving rise to the ascending pharyngeal artery just below the bifurcation. The right external carotid artery branched directly at its origin into the superior thyroid, lingual and occipital arteries and the distal part of the external carotid artery. The latter gave rise to the right facial artery and finally bifurcated into the maxillary and superficial temporal arteries. The right posterior auricular artery arose from the right occipital artery. The finding was unilateral and other vascular anomalies were not observed ${ }^{[11]}$. Anu et al observed that the level of bifurcation of the common carotid artery extended from the second cervical vertebra level to the fourth vertebra. Chang Gung Med J Vol. 34 No. 6 (Suppl)T Ramesh Rao, et al External carotid artery branching level. Anatomical knowledge of the origin, course,and branching pattern of the external carotid artery,as well as the level of bifurcation of the common carotid artery, would be useful to surgeons when ligating vessels in the head and neck regions during surgery and to avoid unnecessary complications during carotid endarterectomy ${ }^{[12]}$. The presence of a high common carotid aretery bifurcation should caution surgeons that the hypoglossal nerve lies in closer proximity and is more vulnerable than in more common presentations. Preoperatively documenting the level of the common carotid aretery bifurcation may be helpful in identifying patients at increased risk of iatrogenic injury ${ }^{[13]}$.

\section{Summary And Conclusion}

External carotid artery through its branches supplies the structures of head and neck region, and variations in its branching pattern were observed. The knowledge of vascular anatomy of external carotid artery is essential for the understanding and interpretation of diagnostic angiograms, as well as performing surgical procedures. . Awareness of details and the topographic anatomy of variations of the external carotid may be useful for both radiologists and vascular surgeons to prevent diagnostic errors, influence surgical tactics and interventional procedures and avoid complications during surgery in the cervical region.

\section{References}

[1]. Takenoshita $\mathrm{H}$ (1983). Case of hypoplasia of the internal carotid artery associated with persistent primitive hypoglossal artery. Kaibogaku Zasshi 58 533-550.

[2]. Dutta AK (1994). Essentials of human anatomy In: Head and Neck. 2nd ed.Calcutta: Current Books International 127-132. 
Variant Branching Patterns Of External Carotid Artery-Pharyngo-Occipital Trunk \& Occipito..

[3]. Nakamasa Hayashi Emiko Hori,yuko ohtani,osamu ohtani,naoya kuwayama et al.,.(2005).Surgical Anatomy of cervical carotid artery for carotid endarterectomy. Neurologica Medico Chirurgica 45(1) 25-30.

[4]. Standring S (2005). Gray's Anatomy. The Anatomical basis of clinical practice. Edinburg. Elsevier Churchill Livingstone 39(31) 543544 .

[5]. Zumre O, Salbacak A, Cicekcibasi AE, Tuncer I and Seker M (2005). Investigation of the bifurcation level of the common carotid artery and variations of the branches of the external carotid artery in human fetuses. Annals of Anatomy 187(4) 361-369.

[6]. Thwin S S, Soe M M, Myint M, Than M and Lwin S (2010). Variations of the origin and branches of the external carotid artery in a human cadaver. Singapore Medical Journal 51(2) e40.

[7]. Drake RL, Vogl W and Mitchell AWM (2005). Gray's Anatomy for Students. Toronto: Elsevier Churchill Livingstone 8911

[8]. Anil A, Turgut Hb, Peker T and Pelin C,(2000). Variations of the branches of the external carotid artery, Gazi Medical journal, 11(2) $81-83$.

[9]. Gurbuz J, Çavdar S, Ozdogmu O. Trifurcation of the left common carotid artery: A case report. Clin Anat 2001;14: 58-61.

[10]. Hollinshead HW, Rosse C. Textbook of Anatomy. 4th ed. Philadelphia: Harper \& Row, 1985:835-6.

[11]. Gluncic V, Petanjek Z, Marusic A, Gluncic I. High bifurcation of common carotid artery, anomalous origin of ascending pharyngeal artery and anomalous branching pattern of external carotid artery. Surg Radiol Anat 2001;23:123-5.

[12]. Anu VR, Pai MM, Rajalakshmi R, Latha VP, Rajanigandha V, D’Costa S. Clinically-relevant variations of the carotid arterial system. Singapore Med J 2007;48: 566

[13]. Lo A, Oehley M, Bartlett A, Adams D, Blyth P, Al-Ali S. Anatomical variations of the common carotid artery bifurcation. ANZ J Surg 2006;76:970-2.

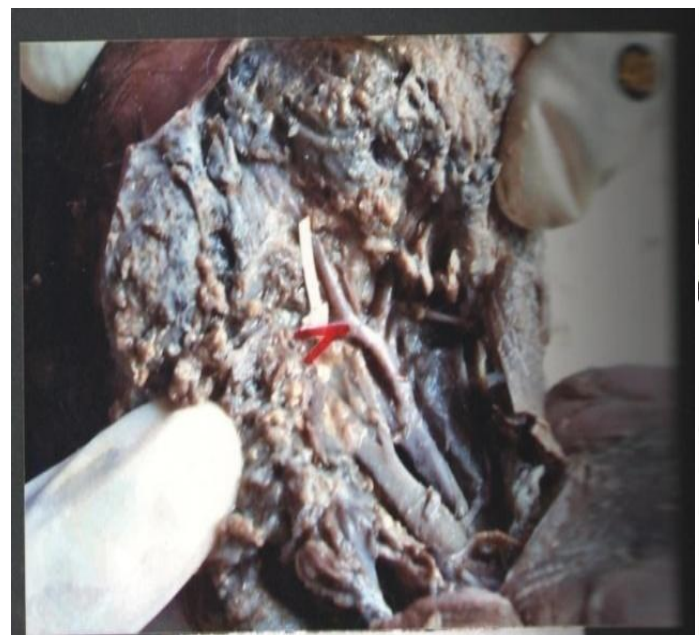

Fig -1, Arrow showing posterior auricular artery arising from occipital artery

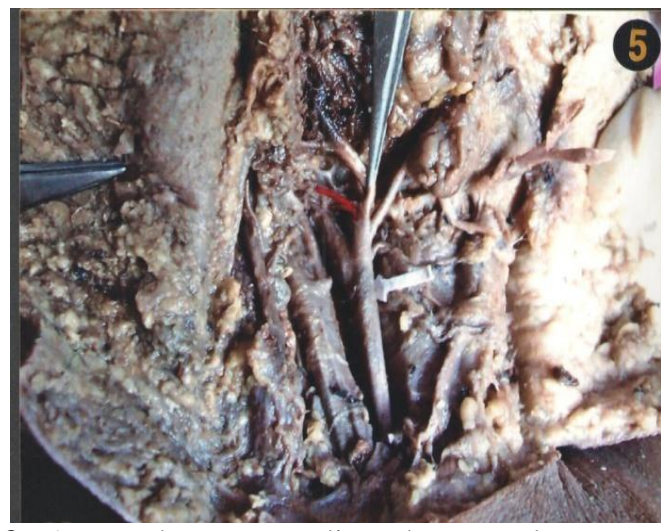

Fig -3, Arrow shows ascending pharyngeal artery arising from occipital artery \&

higher division of common carotid artery

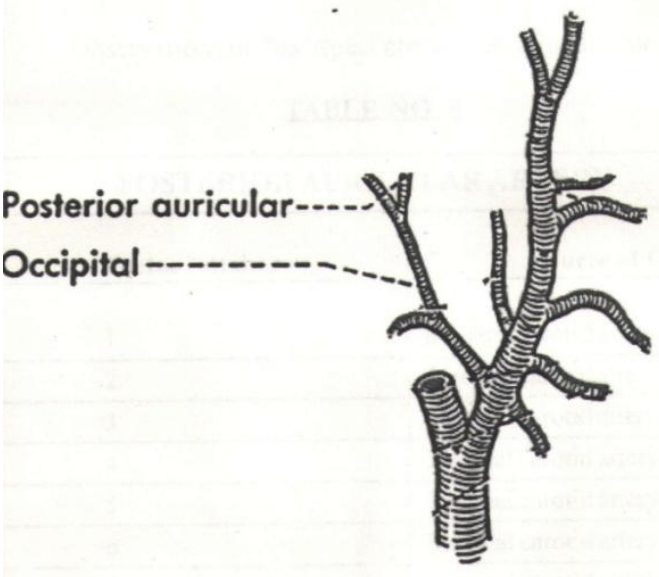

Fig-2, diagram showing posterior auricular artery Arising from Occipital artery

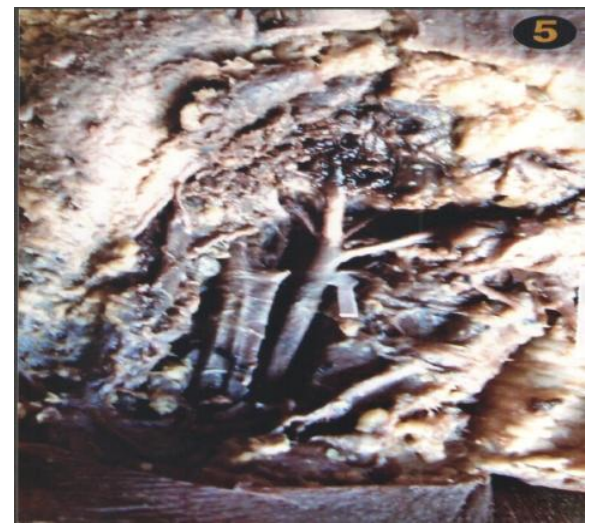

Fig -4, Arrow shows superior thyroid artery arising from common carotid artery. 